\title{
PERENCANAAN SALURAN IRIGASI TERSIER DESA AMBUAU INDAH KEC. LASALIMU SELATAN KAB. BUTON
}

\author{
La Sianto $1^{*}$ \\ Muhammad Chaiddir Hajia ${ }^{2}$ \\ 1,2 Universitas Muhammadiyah Buton, Kota Baubau, Indonesia \\ siantho.civil07@gmail.com ${ }^{{ }^{*} \text { ) }}$ \\ $\underline{\text { muhammadchaiddir@gmail.com }}^{2)}$
}

Kata Kunci: [Irigasi,

Pemerintah Desa,

Perencanan]

Published by:

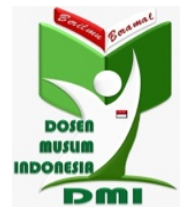

Abstrak: Pada musim kemarau kebutuhan air sawah di Desa Ambuau Indah belum dapat terpenuhi dengan baik, sehingga mempengaruhi hasil produksi petani. Berdasarkan pada kenyataan tersebut, pengabdian ini dilakukan dengan maksud untuk mengkaji pemanfaatan jaringan irigasi serta perencanaan saluraran irigasi tersier pada lahan pertanian di Desa Ambuau Indah, Kec. Lasalimu Selatan Kab. Buton yang lebih efisien untuk mengurangi masalah kekurangan air di petak-petak persawahannya dan meningkatkan efektivitas saluran irigasi itu sendiri. Pada saat pengukuran lapangan, pengurus RT, RW dan ketua kelompok mengundang para peserta untuk mengikuti pemaparan tentang pemahaman Langkah-langka yang akan dilakukan dalam perencanaan ini. Sosialisasi dan pelatihan dilakukan secara bersamasama oleh tim PkM kepada masyarakat, Hasil dari perencanaan ini diharapkan bisa digunakan oleh Pemerintah Desa dan Warga Desa untuk mengatasi kekurangan air di saat musim kemarau tiba sehingga bisa dengan mudah melakukan aktivitas di daeran persawahan tanpa harus memikirkan akan adanya masalah kekurangan air Hasil dari pengabdian masyarakat ini gambar rencana saluran irigasi dan rencana anggaran biaya sehingga bisa memudahkan Pemerintah Desa untuk melakukan pekerjaan irigasi.

Copyright (C) 2022 The Author(s)

This article is licensed under CC BY 4.0 License

\section{(cc) $\mathrm{Br}$}

https://dmi-journals.org/jai/ 


\section{Pendahuluan}

Usaha meningkatkan produktivitas pertanian dan ketahanan pangan, pemenuhan akan air mempunyai peranan penting. Banyak usaha yang dilakukan untuk memenuhinya, antara lain dengan pemanfaatan sumber air permukaan seperti sungai dan waduk, disamping sumber air tanah dalam dengan sumur bor. Selain kebutuhan akan air, tanaman juga membutuhkan tempat untuk tumbuh (lahan atau sawah). Sawah dan lahan yang baik untuk pertanian ialah tanah yang mudah dikerjakan, bersifat produktif dan subur serta cukup akan kebutuhan air.

Lahan pertanian di Desa Ambuau Indah Kecamatan Lasalimu Selatan, Kabupaten Buton yang area persawahannya memanfaatkan jaringan irigasi air permukaan menggunakan air dari sungai melalui beberapa bendung sehingga air dapat sampai ke areal persawahan. Agar jaringan irigasi tersebut dapat digunakan sesuai dengan fungsinya, maka diperlukan adanya perencanaan jaringan irigasi yang efektif dan efisien. Perencanaan jaringan irigasi akan mempengaruhi sistem pemberian air pada petakpetak sawah dan tingkat pelayanan irigasi yang baik untuk diterima petani.

Pada musim kemarau kebutuhan air sawah di Desa Ambuau Indah belum dapat terpenuhi dengan baik, sehingga mempengaruhi hasil produksi petani. Hal demikian terjadi kemungkinan dikarenakan pengolahan air irigasi dan management distribusinya masih kurang merata. Berdasarkan pada kenyataan tersebut, pengabdian ini dilakukan dengan maksud untuk mengkaji pemanfaatan jaringan irigasi serta perencanaan saluraran irigasi tersier pada lahan pertanian di Desa Ambuau Indah, Kec. Lasalimu Selatan Kab. Buton yang lebih efisien untuk mengurangi masalah kekurangan air di petak-petak persawahannya dan meningkatkan efektivitas saluran irigasi itu sendiri.

\section{Metode Pelaksanaan}

Agar perencanaan irigasi ini dapat berjalan lancar, tim pengabdian akan melakukan sosialisasi dan koordinasi dengan pihak Pemerintah Desa dan warga setempam sebelum malakukan pengukuran di Lapangan. Selanjutnya tim pengabdian akan memintah bantuan Pemerintah Desa untuk meninjau lokasi yang akan dijadikan pengabdian.

Pada saat pengukuran lapangan, pengurus RT, RW dan ketua kelompok mengundang para peserta untuk mengikuti pemaparan tentang pemahaman Langkahlangka yang akan dilakukan dalam perencanaan ini. Sosialisasi dan pelatihan dilakukan secara bersama-sama oleh tim PkM kepada masyarakat,

Hasil dari perencanaan ini diharapkan bisa digunakan oleh Pemerintah Desa dan Warga Desa untuk mengatasi kekurangan air di saat musim kemarau tiba sehingga bisa dengan mudah melakukan aktivitas di daeran persawahan tanpa harus memikirkan akan adanya masalah kekurangan air.

\section{Hasil dan Pembahasan}

\section{Pra-Pelaksanaan Kegiatan Pengabdian}

Sebelum melaksanakan kegiatan pengabdian masyarakat, maka tim pengabdian perlu melakukan persiapan sebagai berikut:

a. Tim pengabdian menentukan atau survey lokasi pengabdian

b. Tim Pengabdian mendapatkan Surat Tugas atau rekomendasi dari LPPM Universitas Muhammadiyah buton. 
c. Tim Pengabdian melakukan rapat untuk membagi tugas dan menyusun program kegiatan pengabdian.

d. Tim pengabdian menyusun rencana kerja pengabdian. Dalam hal ini menghubungi Kepala Desa bahwah akan dilakukan pengabdian masyarakat di Desa Ambuau Indah dan akan dilakukan peninjauan lokasi untuk dilakukan perencanaan teknis.

\section{Pelaksanaan Kegiatan Pengabdian}

Pengabdian ini dilaksanakan pada Tanggal 18 Desember 2021 di Desa Ambuau Indah, Kec. Lasalimu Selatan, Kab. Buton

a. Pembukaan. Pembukaan berisi kata sambutan dari ketua tim pengabdian yang berisi tujuan diadakannya pengabdian kepada masyarakat sebagai bentuk Tri Dharama Perguruan Tinggi Dosen Universitas Muhammadiyah Buton. Kepala Desa Ambuau Indah sebagai tuan rumah dari mitra juga memberikan sambutan atas pengabdian yang akan dilaksanakan.

b. Pembahasan. Kegiatan pengabdian ini dimulai sebagai berikut:

1. Sosialisai Bersama pemerintah desa

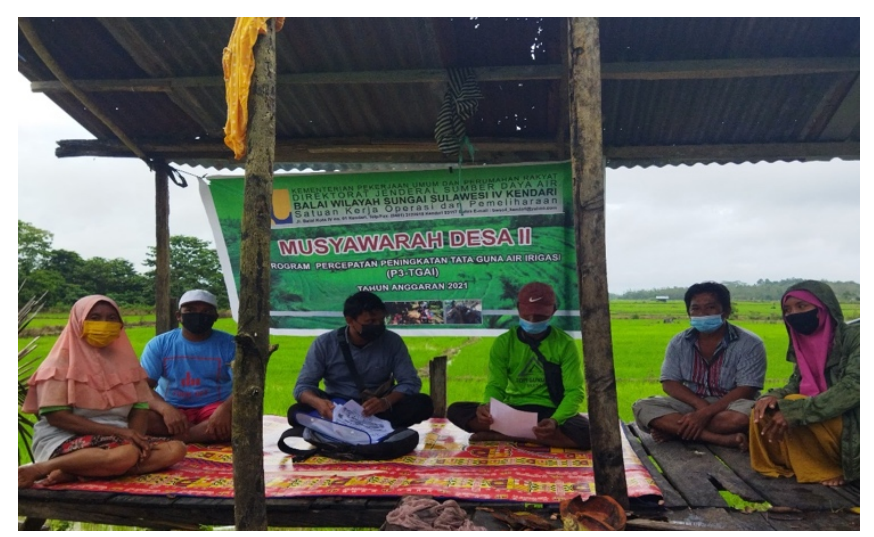

Gambar 1. Sosialisasi Perencanaan Irigasi bersama Pemerintah Desa

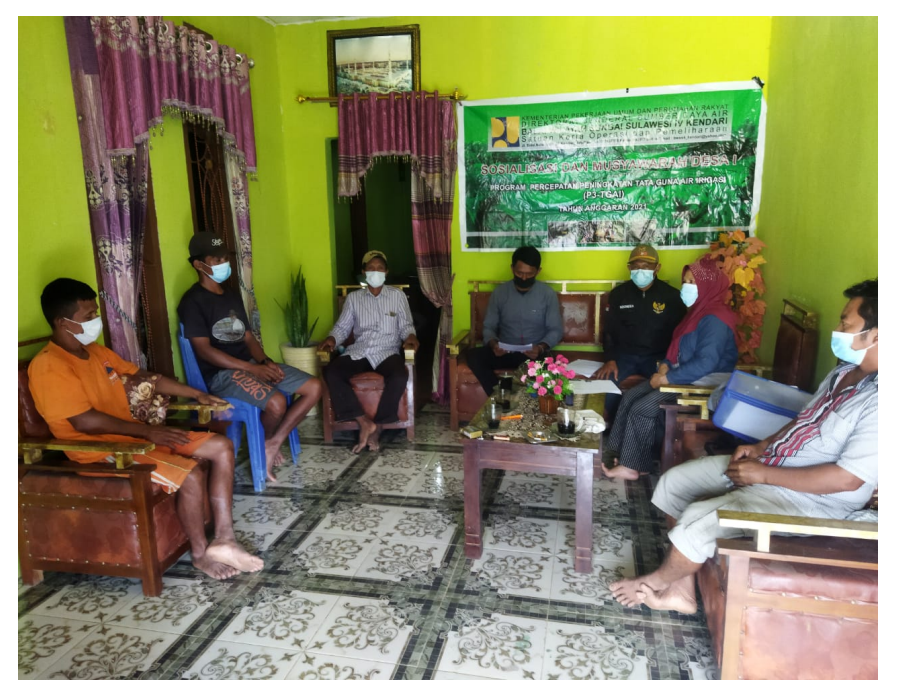

Gambar 2. Sosialisasi Perencanaan Irigasi Bersama Warga Setempat 
2. Melakukan Pengukuran dilokasi perencanaan Bersama Pemerintah Desa

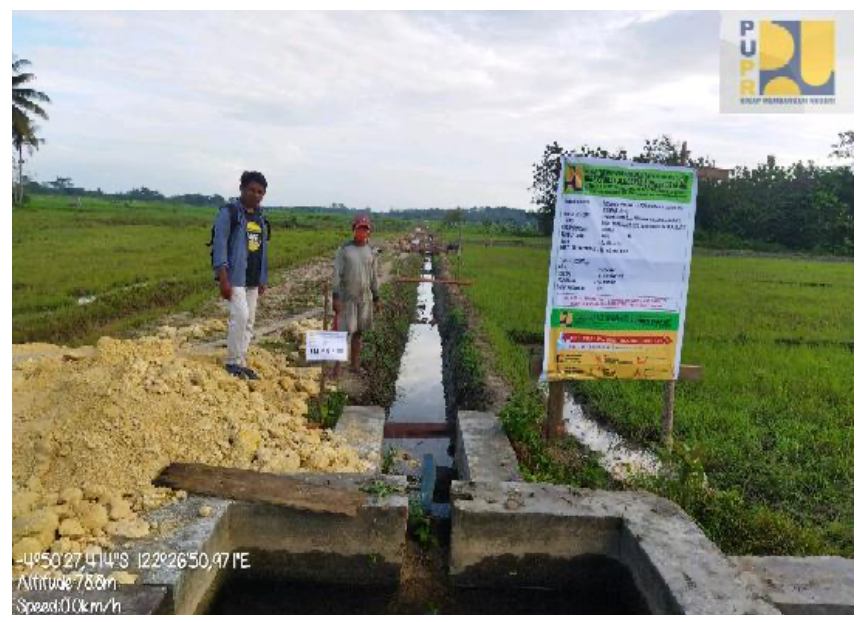

Gambar 3. Pengukuran Lokasi Bersama Pemerintah Desa

3. Perencanaan gambar rencana dan rencana anggaran biaya (RAB) saluran irigasi.

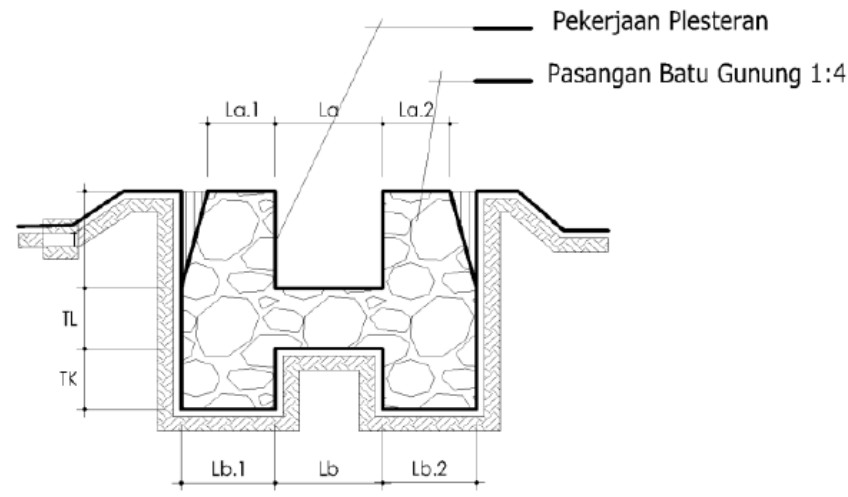

Gambar 4. Gambar Rencana Saluran Irigasi

\begin{tabular}{|c|c|c|c|c|c|c|c|}
\hline No & & Uraian & Satuan & Volume & $\begin{array}{l}\text { Harga Satuan } \\
\quad(\mathrm{Rp})\end{array}$ & Jumlah Biaya (Rp) & Ket \\
\hline$a$ & & b & $c$ & $d$ & e & $f: d x e$ & $g$ \\
\hline \multirow[t]{2}{*}{ A } & \multicolumn{7}{|c|}{ Persiapan, Koordinasi, Perencanaan, Rapat Pelaksanaan, Pelaporan, dan Dokumentasi } \\
\hline & 1 & $\begin{array}{l}\text { Persiapan, Koordinasi, Perencanaan, Rapat Pelaksanaan, Pelaporan, } \\
\text { dan Dokumentasi }\end{array}$ & LS & 1.00 & $9,500,000.00$ & $9,500,000.00$ & \\
\hline \multicolumn{6}{|c|}{ Sub Total A } & $9,500,000.00$ & \\
\hline \multirow[t]{4}{*}{$\mathrm{B}$} & \multicolumn{7}{|c|}{ Pekerjaan saluran dengan cara manual } \\
\hline & 1 & $\begin{array}{l}\text { Galian tanah biasa pada saluran sedalam < } 1 \text { M3 (AHSP } 2016 \text { T.06 } \\
\text { Hal.90) }\end{array}$ & M3 & 74.24 & $56,300.00$ & $4,179,712.00$ & \\
\hline & 2 & $\begin{array}{l}\text { Pasangan Batu dengan mortar tipe N (untuk mutu PP tertentu setara } \\
\text { dengan campuran 1 PC:4 PP) (AHSP 2016 P.01.C Hal.182) }\end{array}$ & M3 & 125.28 & $1,229,300.00$ & $154,006,704.00$ & \\
\hline & 3 & $\begin{array}{l}\text { Plesteran tebal } 1,5 \mathrm{~cm} \text {, dengan mortar tipe S (untuk mutu PP tertentu } \\
\text { setara dengan campuran } 1 \mathrm{PC}: 3 \mathrm{PP} \text { ) (HSP } 2016 \text { P.04.e HAL.196) }\end{array}$ & M2 & 352.64 & $77,499.20$ & $27,329,317.89$ & \\
\hline \multicolumn{6}{|c|}{ Sub Total B } & $185,515,733.89$ & \\
\hline \multicolumn{8}{|c|}{ REKAPITULASI } \\
\hline A & \multicolumn{4}{|c|}{ Persiapan, Koordinasi, Perencanaan, Rapat Pelaksanaan, Pelaporan, dan Dokumentasi } & \multicolumn{2}{|r|}{$9,500,000.00$} & \\
\hline \multirow[t]{4}{*}{$\mathrm{B}$} & \multicolumn{4}{|c|}{ Pekerjaan saluran dengan cara manual } & \multicolumn{2}{|r|}{$185,515,733.89$} & \\
\hline & \multicolumn{4}{|r|}{ Real Cost } & \multicolumn{2}{|r|}{$195,015,733.89$} & \\
\hline & \multicolumn{4}{|c|}{ PEMBULATAN } & \multicolumn{2}{|r|}{$195,000,000.00$} & \\
\hline & & TERBILANG & & & & & \\
\hline
\end{tabular}

Gambar 5. Rencana Anggaran Biaya Saluran Irigasi 


\section{Kesimpulan}

Pelaksanaan kegiatan Pengabdian kepada Masyarakat yaitu perencanaan saluran irigasi tersier sangat baik an lancar sesuai dengan perencanaan kegiatan sebelumnnya. Kegiatan ini diawali dengan sosialisasi bersama Pemerintah Desa, kemudian dilanjutkan dengan tinjau lokasi serta dilakukan pengukuran lapangan. Hasil dari pengabdian masyarakat ini gambar rencana saluran irigasi dan rencana anggaran biaya sehingga bisa memudahkan Pemerintah Desa untuk melakukan pekerjaan irigasi.

Berdasarkan hasil daripada pelaksanaan PKM ini diharapkan bagi Pemerintah Desa Ambuau Indah bisa segara melakukan pekerjaan melalui pengumpulan dana yang anggarannya telah direncanakan secara sistemasi melalui gambar rencana dan rancana anggaran biaya yang ada.

\section{Referensi}

Hamzah, A Yusivian. (2018). Pengembangan Jaringan Irigasi Sawah Daerah Irigasi Sanrego Kab. Bone. Skripsi. Fak Sain Teknologi. UIN Allaudin Makassar.

Martad, Sri Rejeki Laku Utami, Subekhi. (2021). Evaluasi Jaringan Sekunder Dearah Irigasi (D.I) Kenconorejo Kecamatan Tulis Tulis Kabupaten Batang Jawa Tengah. Jurnal Riviews in Civil Engineering. Universitas Selamat Sri.

Nasrudi. (2019). Efisiensi Penyaluran Air Pada Saluran Tersier Di Daerah Irigasi Desa Piong Kecamatan Sanggar Kabupaten Bima. Skripsi. Universitas Muhammadiyah Mataram

Paembonan, Marthen Luther, Reni Oktavia Taru, dkk. (2017). Kajian Perencanaan Saluran Irigasi Sekunder dan Tersier di Desa Samelung Kecamatan Lamasi Kab. Luwu. Jurnal Ilmia Dynamic Saint Jilid III No.1 Oktober 520-536

Kementerian PUPR. (2006). Tentang Irigasi No. 20 Tahun 2016. Jakarta

Linslay, Ray K, Jr, Max A. Kohler dan Paulbus, J.L.H. (1989). Hidrologi Untuk Insinyur Edisi 3. Airlangga. Jakarta

Simorangkir, Haposan Maditua, dkk. (2019). Kinerja Sistem Irigasi Tingkat Tersier UPTD Trimurjo Daerah Irigasi Punggur Utara. Jurnal Teknik Pertanian Lampung. Lampung 